\title{
Mens
}

Revue d'histoire intellectuelle et culturelle

Jean-Pierre Proulx. La genèse de l'école publique et de la démocratie scolaire au Québec : les écoles de syndics 1814-1838, avec la collaboration de Christian Dessureault et Paul Aubin, Québec, Les Presses de l'Université Laval, 2014, 504 p.

\section{Jean-Philippe Croteau}

Volume 16, numéro 2, printemps 2016

URI : https://id.erudit.org/iderudit/1041790ar

DOI : https://doi.org/10.7202/1041790ar

Aller au sommaire du numéro

Éditeur(s)

Centre de recherche en civilisation canadienne-française

\section{ISSN}

1492-8647 (imprimé)

1927-9299 (numérique)

Découvrir la revue

Citer ce compte rendu

Croteau, J.P. (2016). Compte rendu de [Jean-Pierre Proulx. La genèse de l'école publique et de la démocratie scolaire au Québec : les écoles de syndics 1814-1838, avec la collaboration de Christian Dessureault et Paul Aubin, Québec, Les Presses de l'Université Laval, 2014, 504 p.] Mens, 16(2), 116-120.

https://doi.org/10.7202/1041790ar d'utilisation que vous pouvez consulter en ligne.

https://apropos.erudit.org/fr/usagers/politique-dutilisation/ 
les étudiants et les chercheurs intéressés par la question de l'indépendantisme québécoise auront désormais une synthèse historique à portée de main afin de comprendre toute la complexité et la richesse de ce pan de l'histoire politique du Québec.

- Jean-Philippe Carlos

Département d'histoire

Université de Sherbrooke

Jean-Pierre Proulx. La genèse de l'école publique et de la démocratie scolaire au Québec : les écoles de syndics 18141838, avec la collaboration de Christian Dessureault et Paul Aubin, Québec, Les Presses de l'Université Laval, 2014, 504 p.

Jean-Pierre Proulx est bien connu pour ses interventions publiques dans le domaine de l'éducation, comme journaliste, professeur à la Faculté d'éducation de l'Université de Montréal et président du groupe de travail ministériel sur la place de la religion à l'école et du Conseil supérieur de l'éducation. Cette fois-ci, il intervient, avec la collaboration de Christian Dessureault et Paul Aubin, à titre d'historien pour examiner l'histoire des écoles de syndics et reconstituer ainsi la genèse de l'école publique et de la démocratie scolaire au Québec. Une histoire méconnue, présentée le plus souvent par l'historiographie comme un épisode raté pour mettre en place la première école publique au Québec.

Jean-Pierre Proulx nous montre, par l'étude minutieuse d'un corpus de sources primaires diversifiées, que la réalité fut beaucoup plus complexe. Malgré une vie très courte - à peine sept ans, de 1829 à 1836 - les écoles de syndics, en raison de leur caractère démocratique et égalitaire, ont constitué la première tentative pour instaurer une école publique et favoriser la participation populaire à la "chose " éducative. Selon l'auteur, l'école de syndics apparaîtrait comme l'ancêtre de l'école publique québécoise, ne serait-ce que par les valeurs 
qu'elle professait et qui sont celles de l'école québécoise encore aujourd'hui.

Loin de rédiger un livre qui revisite les études antérieures, JeanPierre Proulx entreprend une réflexion sur les choix qui ont amené la Chambre d'assemblée à confier l'éducation à des élus locaux et sur l'implantation de la démocratie scolaire avec ses nécessaires dimensions politiques, administratives, pédagogiques et financières. Il innove, comparativement à ses prédécesseurs, en bonifiant considérablement son corpus documentaire. Il a étudié méthodiquement les journaux de l'époque, les greffes de notaire du district de Montréal qui relatent les élections de syndics, les journaux de la Chambre d'assemblée, les archives du Public Record Office (PRO) du Royaume-Uni ainsi que les archives coloniales conservées à Bibliothèque et Archives Canada. Il en résulte un portrait fouillé et assez complet de la question qui ne répond pas, certes, à toutes les questions, comme le rappelle régulièrement l'auteur en raison des limites posées par les sources primaires, mais qui offre tout de même une interprétation convaincante et efficace.

L'intérêt de cet ouvrage se situe à deux niveaux essentiellement. Tout d'abord, il apporte une contribution majeure à l'histoire du mouvement patriote en s'intéressant - et l'auteur est l'un des premiers à le faire - à sa doctrine relative à l'éducation. Les autres auteurs s'étaient plutôt intéressés à l'aspect politique, notamment républicain, du projet patriote. Jean-Pierre Proulx brosse un portrait nuancé qui relativise l'antagonisme entre libéraux et conservateurs. En effet, les promoteurs des écoles de syndics valorisaient une institution scolaire laïque, démocratique et égalitaire, accessible à tous. Ils ne niaient toutefois pas l'importance de l'éducation morale et ne tombaient pas dans l'anticléricalisme puisqu'ils se montraient favorables à la participation du clergé à l'administration des syndics. Ils étaient toutefois farouchement opposés à une instruction uniquement religieuse et au monopole du clergé en matière d'éducation.

De plus, l'auteur montre bien que l'établissement des écoles de syndics s'inscrit dans un vaste mouvement intellectuel européen et 
nord-américain qui visait à promouvoir l'instruction publique et que leurs partisans s'inspiraient largement des expériences effectuées ailleurs, tout particulièrement dans l'État de New York, comme en témoignent les écrits de la presse. Là où le bât blesse, c'est lorsque l'auteur tente de catégoriser le libéralisme des promoteurs des écoles de syndics en le mesurant essentiellement à la typologie de Michel Ducharme, dans son livre Le concept de liberté au Canada. Un corpus historiographique aussi mince apparaît un peu réducteur pour trancher la question de la nature du libéralisme des promoteurs des écoles de syndics. La simplicité de ses conclusions contraste avec l'enquête minutieuse de l'auteur et sa rigueur pour reconstituer à la fois les débats entourant les écoles de syndics et la mise en place de ce réseau scolaire.

L'autre contribution importante de cet ouvrage porte sur la démocratie scolaire vécue sous le régime des écoles de syndics. L'auteur a d'autant plus relevé le défi que les sources primaires comportaient des carences et des lacunes qui rendaient l'exercice périlleux. Cependant, le résultat est réussi. L'auteur reconstitue fort bien les rouages de l'élection des syndics et parvient à dresser un profil socioprofessionnel des représentants scolaires. Il invalide ainsi l'interprétation voulant que les syndics aient été une créature politique servant la lutte du Parti patriote contre le pouvoir colonial. Ainsi, il montre que le choix des représentants scolaires n'avait pas le caractère politique qu'on lui a prêté et que les syndics avaient à leur tête des curés, des cultivateurs et des anglophones. L'ouvrage fait état des efforts des représentants scolaires pour rendre l'école la plus accessible possible lui conférant son caractère démocratique et égalitaire, hausser la compétence des instituteurs et des institutrices et assurer tant bien que mal un financement adéquat. À ce titre, Jean-Pierre Proulx rejoint les travaux d'une historiographie amorcée depuis quelques décennies déjà qui examine les dynamiques scolaires au sein des collectivités locales. Il contribue à l'avancement de nos connaissances sur la participation des acteurs locaux dans la mise en place d'un réseau d'écoles publiques. 
Les anglophones sont les grands absents de cet ouvrage. À part quelques références sur leur élection à la tête des syndics et le financement alloué aux townships, on apprend peu de chose sur la participation des anglophones à la mise en place de ce réseau scolaire, sur le rôle joué par ces écoles dans le processus de scolarisation de la minorité anglaise en milieu rural et, surtout, sur le discours de la presse anglophone portant sur une éducation libérale, démocratique et égalitaire. Or, trop souvent associée à l'oligarchie coloniale, la minorité anglophone ne constituait pas un bloc culturel, politique, social, voire religieux. À l'instar des francophones, les anglophones ont sans doute usé de plusieurs stratégies scolaires sur la scène locale pour avoir accès à une instruction publique. Une étude sur cette question reste encore à faire.

Dans la conclusion, l'auteur rappelle que l'école de syndics constitue le fondement du système d'éducation québécois. L'école des commissaires, fondée entre 1841 et 1846, a continué dans son sillon en confiant l'autonomie en matière d'éducation aux collectivités locales. Cependant, l'auteur aurait pu s'étendre davantage sur le parallèle entre l'école de syndics et celle des commissaires. En effet, la gratuité scolaire instaurée à l'école primaire au tournant du xx siècle, le développement de l'enseignement commercial et technique ainsi que de l'enseignement secondaire public dans les années 1920 pour assurer la scolarisation de la population québécoise des milieux populaires et ruraux ne sont-ils pas des mesures inscrites dans l'esprit des écoles de syndics? À cet égard, c'est toute une réflexion sur la persistance du caractère libéral, démocratique et égalitaire dans le projet éducatif des écoles de syndics et celles des commissaires qui pourrait être approfondie.

Il reste que la contribution la plus importante de Jean-Pierre Proulx est d'avoir réhabilité une histoire de l'éducation qui a longtemps associé la première moitié du XIX siècle à une forme de "Grande Noirceur ". Il apparaît au contraire que les élites bas-canadiennes de l'époque ont fait de l'éducation une préoccupation majeure et qu'en dépit des obstacles politiques et de la faiblesse des moyens financiers, 
elles sont parvenues à mettre en place un réseau scolaire destiné à former des citoyens démocrates et à assurer le progrès culturel, social et économique des Canadiens français. Jean-Pierre Proulx a relevé que le quart des enfants des milieux ruraux ont fréquenté les écoles de syndics au cours d'une période de sept ans. Le résultat n'est pas si mal après tout pour une première tentative...

\section{- Jean-Philippe Croteau \\ Département d'études françaises}

Collège des cultures et des langues étrangères

Université du Sichuan

\section{Jean-Philippe Warren. HonoréBeaugrand: la plume et l'épée (1848-1906), Montréal, Éditions du Boréal, 2015, 532 p.}

N'eut été de la station terminus de la ligne verte du métro de Montréal, Honoré Beaugrand aurait été depuis longtemps oublié. Ce nouveau livre de Jean-Philippe Warren est la première biographie de cet homme "moderne " qui a marqué la vie journalistique, littéraire, intellectuelle et politique de son peuple. Ce n'est pas un travail facile. Beaugrand n'a pas laissé d'archives, et sa trace est dépistée grâce à la presse et à ses articles de journaux (la plupart non signés), à des bribes de témoignages et à des sources secondaires. Au fil de sept chapitres comportant plus de soixante-dix pages chacun, Warren découpe les grandes étapes de cette vie fascinante.

Né en l'année fatidique de 1848, le jeune Marie-Louis-Honoré grandit dans une famille plutôt patriote de Lanoraie, qui aime se rappeler les beaux jours des promesses de Papineau et des siens. Fils de navigateur, il fait des études au Collège Joliette et se laisse tenter par la prêtrise, mais découvre en quelques semaines que la foi ne bat pas assez fort dans sa poitrine. Bien au contraire, son cœur bat plutôt au rythme du tambour militaire, l'objet du deuxième chapitre. Il reçoit sa formation de militaire (une affaire de quelques mois) et lance les dés du destin. Il quitte le pays quelques mois après la Conférence de Québec, qui jette les fondations de la Confédération. 